\title{
A-94964, a Novel Inhibitor of Bacterial Translocase I, Produced by Streptomyces sp. SANK 60404
}

\author{
I. Taxonomy, Isolation and Biological Activity
}

\author{
Ryo Murakami, Yoko Fujita, Masaaki Kizuka, Tomoka Kagawa, Yasunori Muramatsu, \\ Shunichi Miyakoshi, Toshio Takatsu, Masatoshi Inukai
}

Received: April 3, 2008 / Accepted: August 18, 2008

(C) Japan Antibiotics Research Association

\begin{abstract}
Bacterial phospho- $N$-acetylmuramyl-pentapeptide translocase (translocase I: EC 2.7.8.13) is a key enzyme in peptidoglycan biosynthesis, and a known target of antibiotics. Here we report a novel nucleoside inhibitor against translocase I, A-94964, isolated from the culture broth of the strain Streptomyces sp. SANK 60404. A-94964 inhibited bacterial translocase $\mathrm{I}$ with $\mathrm{IC}_{50}$ value of $1.1 \mu \mathrm{g} / \mathrm{ml}$, and showed antimicrobial activities against Staphylococcus aureus and Enterococcus faecalis with MIC of 100 and $50 \mu \mathrm{g} / \mathrm{ml}$, respectively. A-94964 did not show cytotoxicity against mammalian cell lines.
\end{abstract}

Keywords A-94964, translocase I, peptidoglycan, nucleoside antibiotic, antimicrobial activity, Streptomyces sp., tunicamycin

\section{Introduction}

The emergence of bacterial antibiotic resistance is a serious threat to the antibiotic therapy. One of the attractive strategies to overcome this problem is to find new antibacterial agents active to novel targets. Enzymes involved in the bacterial cell wall biosynthesis pathway are essential for growth, and attractive targets for new antimicrobial agents. These enzymes include the first enzyme involved in the membrane stage of peptidoglycan synthesis, phospho- $N$-acetylmuramylpentapeptide translocase (translocase I), that catalyzes the transfer of MurNAc-pentapetide from UDP-MurNAcpentapetide to the lipid carrier undecaprenyl phosphate to form lipid I. There are several known translocase I inhibitors [1], such as mureidomycins [2], pacidamycins [3], napsamycins [4], liposidomycins [5], tunicamycin [6], capuramycins [7 13], muraymycins [14] and caprazamycins $[15,16]$. They exhibit antimicrobial activity against various strains including multidrug-resistant ones, and show bactericidal activity $[15,17,18]$. Thus translocase I has been an established target for the search of novel antibiotics.

In the course of our screening for bacterial translocase I inhibitors, we found inhibitory activity in the culture broth of Streptomyces sp. SANK 60404. The strain produced a novel nucleoside antibiotic with a phosphoric ester designated as A-94964 (Fig. 1). In this report, we describe
R. Murakami (Corresponding author): Exploratory Research Laboratories II, Daiichi-Sankyo Co., Ltd., 1-16-13 Kitakasai, Edogawa-ku, Tokyo 134-8630, Japan, E-mail: murakami.ryo.bw@ daiichisankyo.co.jp

Y. Fujita, M. Kizuka, T. Kagawa, T. Takatsu: Exploratory Research Laboratories I, Daiichi-Sankyo Co., Ltd., 1-2-58 Hiromachi, Shinagawa-ku, Tokyo 140-8710, Japan

Y. Muramatsu: Exploratory Research Laboratories I, Daiichi-
Sankyo Co., Ltd., 1-16-13 Kitakasai, Edogawa-ku, Tokyo 1348630, Japan

S. Miyakoshi: Gunma National College of Technology, 580, Toriba-machi, Maebashi, Gunma prefecture 371-8530, Japan

M. Inukai: Department of Pharmaceutical Sciences, International University of Health and Welfare, 2600-1, Kitakanemaru, Ohtawara, Tochigi prefecture 324-8501, Japan 


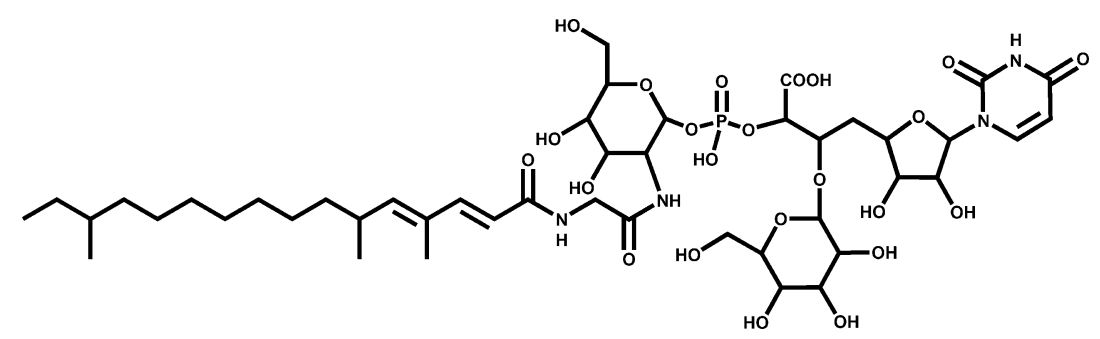

Fig. 1 Structure of A-94964.

the taxonomy and fermentation of the producing microorganism, as well as isolation and biological activities of A-94964.

\section{Materials and Methods}

\section{Materials}

Undecaprenyl phosphate was purchased from Larodan Fine Chemicals. Preparation methods for translocase I and a fluorescent substrate (UDP-MurNAc-L-Ala- $\gamma$-D-Glu- $m$ DAP-[ $N^{\varepsilon}$-dansyl]-D-Ala-D-Ala) was previously reported [10]. Tunicamycin was purchased from Sigma.

\section{Taxonomy of the Producing Organism}

The producing organism, strain SANK 60404, was isolated from a soil sample collected in Okinawa, Japan. The methods and media described by the International Streptomyces Project (ISP) [19] and Waksman [20] were used to determine the morphological characterizations and the physiological properties of the producing organism. The cell walls and whole-cell hydrolysates were analyzed by the methods of Hasegawa et al. [21]. The 16S rDNA was amplified by the polymerase chain reaction using genomic DNA of the strain and sequenced. The most related sequences were searched using the BLAST algorithm in the National Center for Biotechnology Information (NCBI).

Phylogenetic analysis of the $16 \mathrm{~S}$ rDNA sequences was performed according to the method of Nakagawa and Kawasaki [22]. A phylogenetic tree was constructed using the neighbor-joining methods [23] in MEGA, version 4.0 [24].

\section{Fermentation of Strain SANK 60404}

A loopful amount of a culture of strain SANK 60404 was inoculated into each of three 500-ml Erlenmeyer flasks containing $80 \mathrm{ml}$ of sterilized seed medium consisting of glucose $1.0 \%$, soluble starch $4.0 \%$, pressed yeast $0.45 \%$, Polypepton (Nihon Seiyaku) 1.0\%, Corn steep liquor 0.5\%,
$\mathrm{CoCl}_{3} \cdot 6 \mathrm{H}_{2} \mathrm{O} \quad 0.0001 \%, \mathrm{KH}_{2} \mathrm{PO}_{4} \quad 0.05 \%, \quad \mathrm{ZnSO}_{4} \cdot 7 \mathrm{H}_{2} \mathrm{O}$ $0.001 \%, \mathrm{Mg}_{3}\left(\mathrm{PO}_{4}\right)_{2} \cdot 8 \mathrm{H}_{2} \mathrm{O} 0.005 \%, \mathrm{NiSO}_{4} \cdot 6 \mathrm{H}_{2} \mathrm{O} 0.0001 \%$ and $\mathrm{CB}-442$ (NOF Co., Ltd.) $0.005 \%, \mathrm{pH}$ 7.0. The inoculated flasks were incubated on a rotary shaker $(210 \mathrm{rpm})$ at $28^{\circ} \mathrm{C}$ for 3 days. Then $2.0 \mathrm{ml}$ aliquots of the culture were transferred into each of twenty-six 500-ml Erlenmeyer flasks containing $80 \mathrm{ml}$ of sterilized production medium with the same composition as that of the seed medium. The inoculated flasks were incubated on a rotary shaker $(210 \mathrm{rpm})$ at $28^{\circ} \mathrm{C}$ for 7 days.

\section{Measurement of Translocase I Inhibitory Activity}

The measurement of translocase I inhibitory activity was carried out in 96-well microtitre polystyrene plates consisting of the following: $100 \mu \mathrm{l}$ containing $100 \mathrm{mM}$ Tris- $\mathrm{HCl}$ ( $\mathrm{pH}$ 7.5), $50 \mathrm{mM} \mathrm{KCl}, 25 \mathrm{mM} \mathrm{MgCl}_{2}, 0.8 \%$ Triton X-100, $166 \mu \mathrm{M}$ undecaprenyl phosphate, and $70 \mu \mathrm{M}$ UDP-MurNAcL-Ala- $\gamma$-D-Glu- $m$-DAP-[ $N^{\varepsilon}$-dansyl]-D-Ala-D-Ala. The reaction was initiated by the addition of enzyme (0.625 $2.5 \mu \mathrm{g}$ protein). The enzyme activity was monitored by measuring the increase in fluorescence at $538 \mathrm{~nm}$ (excitation at $355 \mathrm{~nm}$ ).

\section{Antimicrobial Activities}

MICs were determined by the agar dilution method using Mueller Hinton agar (Becton Dickinson and Company).

\section{Cell Culture}

HeLa (cervix adenocarcinoma) and A549 (lung adenocarcinoma) were cultured in DMEM supplemented with $10 \%$ FBS.

\section{Assay of Cytotoxicity}

The cytotoxicity was determined by measuring the reduction product of 3-[4,5-dimethylthiazol-2-yl]-2,5diphenyltetrazolium bromide (MTT) [25]. In brief, HeLa and A549 were seeded at $5 \times 10^{3}$ cells/well in 96-well microplates and cultured overnight. The cells were treated with various concentrations of A-94964 and tunicamycin 
for 72 hours. Growth was measured by formazan formation (detected at $570 \mathrm{~nm}$ ) after treatment of the cells with $0.5 \mathrm{mg} / \mathrm{ml}$ of MTT for 4 hours at $37^{\circ} \mathrm{C}$. $\mathrm{IC}_{50}$ values were determined from the dose-response curves of growth inhibition.

\section{General Experimental Procedures}

Fluorescence was measured at room temperature on a fluorescence spectrophotometer, Fluoroskan Ascent (Labsystems).

\section{Results}

\section{Taxonomy}

Strain SANK 60404 formed straight to flexuous spore chains. Most spores were oblong and $0.4 \sim 0.7 \times 0.8 \sim$ $1.2 \mu \mathrm{m}$ in size with smooth surface (Fig. 2). The cultural characteristics of the various agar media at $28^{\circ} \mathrm{C}$ for 14 days are presented in Table 1. The physiological properties of the strain and the type of carbon source utilized are summarized in Table 2 . The vegetative mycelium was pale

Table 1 Culture characteristics of strain SANK 60404

\begin{tabular}{|c|c|c|}
\hline \multirow{4}{*}{$\begin{array}{l}\text { Yeast extract-malt extract agar } \\
\text { (ISP-2) }\end{array}$} & $\mathrm{G}^{\mathrm{a}}$ : & Abundant, raised, yellowish gray \\
\hline & $\mathrm{AM}^{\mathrm{a}}$ : & Abundant, velvety, yellowish gray \\
\hline & $\mathrm{R}^{\mathrm{a}}$ & Yellowish gray \\
\hline & $\mathrm{SP}^{\mathrm{a}}$ & None \\
\hline \multirow{4}{*}{$\begin{array}{l}\text { Oatmeal agar } \\
\text { (ISP-3) }\end{array}$} & G: & Good, flat, white \\
\hline & AM: & Good, velvety, light brownish gray \\
\hline & $\mathrm{R}:$ & White \\
\hline & SP: & None \\
\hline \multirow{4}{*}{$\begin{array}{l}\text { Inorganic salts-starch agar } \\
\text { (ISP-4) }\end{array}$} & G: & Abundant, raised, yellowish gray \\
\hline & AM: & Abundant, velvety, light brownish gray \\
\hline & $\mathrm{R}:$ & Yellowish gray \\
\hline & SP: & None \\
\hline \multirow{4}{*}{$\begin{array}{l}\text { Glycerol-asparagine agar } \\
\text { (ISP-5) }\end{array}$} & G: & Good, raised, yellowish gray \\
\hline & AM: & Good, white \\
\hline & $\mathrm{R}:$ & Yellowish gray \\
\hline & SP: & None \\
\hline \multirow{4}{*}{$\begin{array}{l}\text { Tyrosine agar } \\
\text { (ISP-7) }\end{array}$} & G: & Abundant, raised, pale brown \\
\hline & AM: & Abundant, velvety, brownish gray \\
\hline & $\mathrm{R}:$ & Pale brown \\
\hline & SP: & Black \\
\hline \multirow[t]{4}{*}{ Sucrose-nitrate agar } & G: & Good, flat, white \\
\hline & AM: & Good, velvety, pale orange \\
\hline & $\mathrm{R}:$ & White \\
\hline & SP: & None \\
\hline \multirow[t]{4}{*}{ Glucose-asparagine agar } & G: & Poor to moderate, flat, yellowish gray \\
\hline & AM: & Poor, white \\
\hline & $\mathrm{R}:$ & Yellowish gray \\
\hline & SP: & None \\
\hline \multirow{4}{*}{$\begin{array}{l}\text { Nutrient agar } \\
\text { (Difco) }\end{array}$} & G: & Poor to moderate, flat, yellowish gray \\
\hline & AM: & None \\
\hline & $\mathrm{R}:$ & Yellowish gray \\
\hline & SP: & None \\
\hline \multirow[t]{4}{*}{ Potato extract-carrot extract agar } & G: & Poor to moderate, flat, white \\
\hline & AM: & Abundant, velvety, pale brown \\
\hline & $\mathrm{R}:$ & White \\
\hline & SP: & None \\
\hline \multirow[t]{4}{*}{ Water agar } & G: & Poor, flat, white \\
\hline & AM: & Poor, velvety, pale brown \\
\hline & $\mathrm{R}:$ & White \\
\hline & SP: & None \\
\hline
\end{tabular}

${ }^{a}$ G: growth, AM: aerial mycelium, R: reverse, SP: soluble pigment. 
Table 2 Physiological properties of strain SANK 60404

\begin{tabular}{|c|c|}
\hline Hydrolysis of starch & + \\
\hline Liquefaction of gelatin & - \\
\hline Reduction of nitrate & + \\
\hline Coagulation of milk & + \\
\hline Peptonization of milk & + \\
\hline \multicolumn{2}{|l|}{ Production of melanoid pigment } \\
\hline ISP1 & - \\
\hline ISP6 & + \\
\hline ISP7 & + \\
\hline \multicolumn{2}{|l|}{ Decomposition of } \\
\hline Casein & + \\
\hline Tyrosine & + \\
\hline Xanthine & + \\
\hline Growth temperature (ISP9) & $8 \sim 45^{\circ} \mathrm{C}$ \\
\hline Optimum growth temperature & $17 \sim 28^{\circ} \mathrm{C}$ \\
\hline Sodium chloride resistance & $5 \%$ \\
\hline \multicolumn{2}{|l|}{ Utilization of } \\
\hline D-Glucose & + \\
\hline L-Arabinose & + \\
\hline D-Xylose & + \\
\hline Inositol & + \\
\hline D-Mannitol & - \\
\hline D-Fructose & + \\
\hline L-Rhamnose & + \\
\hline Sucrose & - \\
\hline Raffinose & - \\
\hline
\end{tabular}

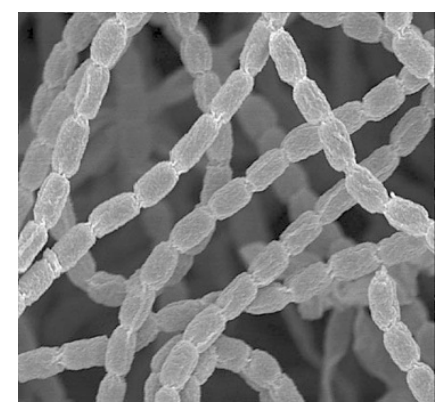

Fig. 2 Scanning electron micrograph of strain SANK 60404.

yellowish brown to yellowish gray.

The whole-cell hydrolysates of the strain contained LLdiaminopimelic acid. An almost complete 16S rDNA sequence (1447 bp) was determined so as to make phylogenetic tree based on 16S rDNA sequences of strain SANK 60404 and the genus Streptomyces including other producing organisms of translocase I inhibitors (Fig. 3). The highest 16S rDNA sequence similarities were found with "Streptomyces coeruleoaurantiacus" NBRC 14526
(99.8\%) which is not a validly established species. Based on the taxonomic properties and the $16 \mathrm{~S}$ rDNA gene sequence, the strain was identified as Streptomyces sp. SANK 60404. The strain SANK 60404 was deposited in the International Patent Organism Depositary, National Institute of Advanced Industrial Science and Technology, Ibaraki Prefecture, Japan with the accession number FERM BP-10112.

\section{Isolation}

The isolation procedure of A-94964 is outlined in Fig. 4. First, the culture broth (2.0 liters) was extracted with an equal volume of acetone and was centrifuged (3,000 rpm, 10 minutes). The supernatant was concentrated to a small volume and was adjusted to $\mathrm{pH} 3.0$ with $1.0 \mathrm{M} \mathrm{HCl}$. Then the supernatant was adsorbed on a Diaion HP20 column (400 ml, Mitsubishi Chemical Corporation). The column was washed with $30 \% \mathrm{Me}_{2} \mathrm{CO}$ (1.4 liters) and the active substance was eluted with $50 \% \mathrm{Me}_{2} \mathrm{CO}$ (1.4 liters). The active eluate was concentrated in vacuo and lyophilized to give a crude powder $(1.3 \mathrm{~g})$. Then $300 \mathrm{mg}$ portion of this crude powder were dissolved in $1.0 \mathrm{ml}$ of $15 \% \mathrm{MeCN}$ with $10 \mathrm{mM}$ ammonium bicarbonate and adsorbed on a column of Diaion CHP20P. The column was washed with $15 \%$ $\mathrm{MeCN}(200 \mathrm{ml})$ and $20 \% \mathrm{MeCN}(200 \mathrm{ml})$, and the active substances was eluted with $25 \% \mathrm{MeCN}$ (400 ml). The active fraction was concentrated in vacuo and lyophilized to give a crude powder $(64 \mathrm{mg})$. Then $50 \mathrm{mg}$ portion of this crude powder as dissolved in $4.0 \mathrm{ml}$ of $50 \% \mathrm{MeOH}$ with $1.5 \%$ triethylamine phosphate $(\mathrm{pH} 3.0)$ and applied on a preparative HPLC, in which CAPCELL PAK C18UG120 was developed with $50 \% \mathrm{MeCN}$ with $1.0 \%$ triethylamine phosphate ( $\mathrm{pH}$ 3.0). The active fractions were collected, desalted with a Diaion HP20 column, and lyophilized to give a white powder of A-94964 (18.9 mg).

\section{Biological Activities of A-94964}

A-94964 inhibited translocase $\mathrm{I}$ with $\mathrm{IC}_{50}$ values of $1.1 \mu \mathrm{g} / \mathrm{ml}$ (In this assay, tunicamycins showed $\mathrm{IC}_{50}$ values of $5.0 \mu \mathrm{g} / \mathrm{ml}$ ). A-94964 showed antimicrobial activities against Staphylococcus aureus and Enterococcus faecalis with MIC of 100 and $50 \mu \mathrm{g} / \mathrm{ml}$, respectively (Table 3 ).

\section{Cytotoxic Activities}

In in vitro cytotoxicity of A-94964 estimated by MTT assay, this compound exhibited no cytotoxic effect up to $100 \mu \mathrm{g} / \mathrm{ml}$ against the human cancer cell lines, HeLa and A549, while tunicamycins showed potent cytotoxicity against these cell lines $\left(\mathrm{IC}_{50}\right.$ values against HeLa and $\mathrm{A} 549$ were 0.075 and $0.072 \mu \mathrm{g} / \mathrm{ml}$, respectively). 


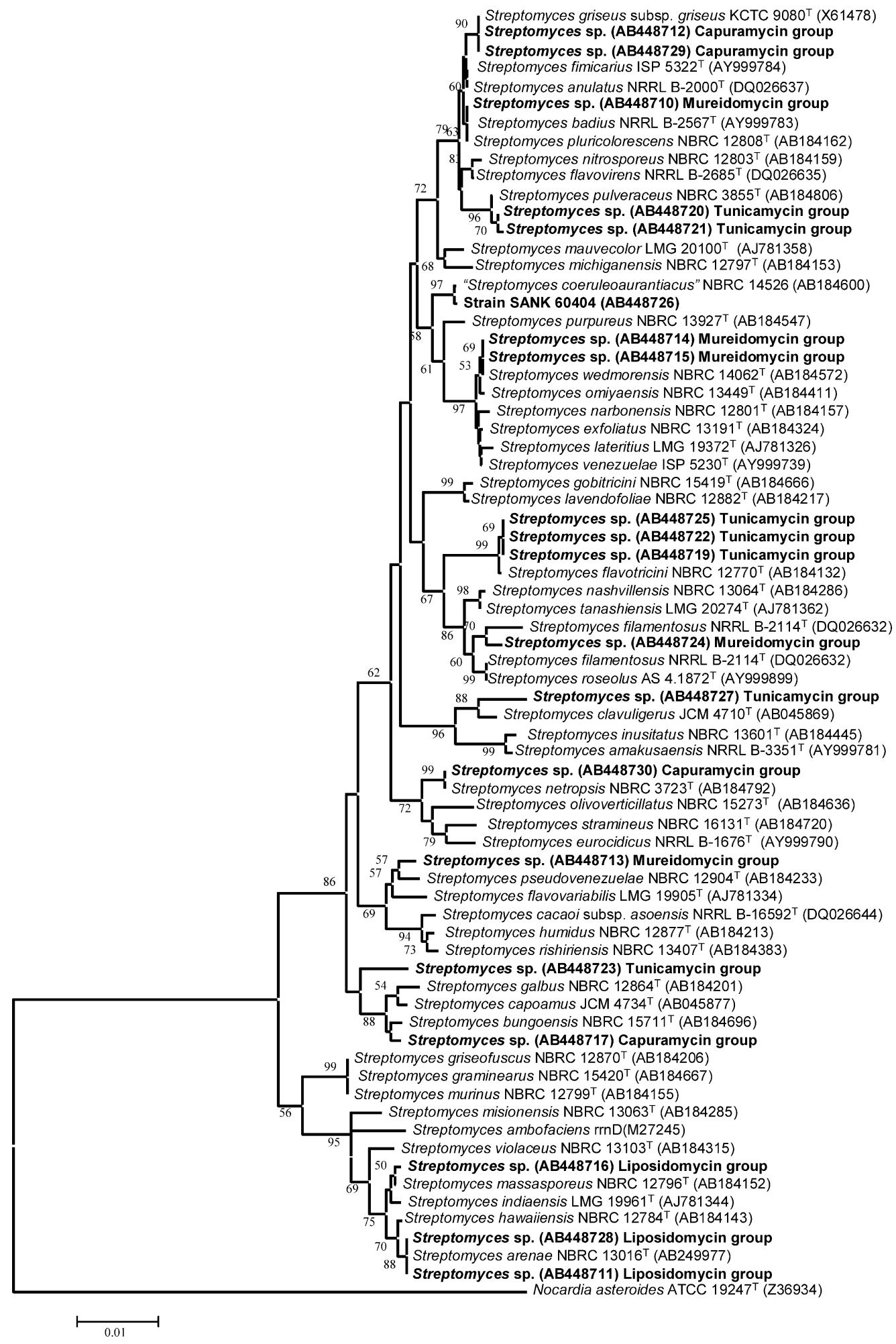

Fig. 3 Phylogenetic tree showing the positions of strain SANK 60404 and other producing organisms of other translocase I inhibitors based on sequence of $16 \mathrm{~S}$ rDNA (ca. 1,400 nucleotides) analysis.

The numbers on the branches are confidence limits (expressed as percentages) estimated from a bootstrap analysis with 1000 replicates (above $50 \%$ are indicated). 


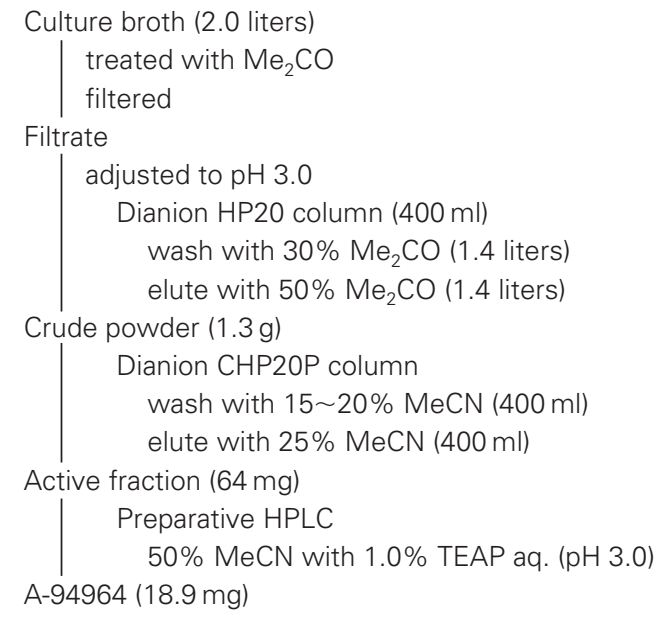

Fig. 4 Isolation procedure of A-94964.

\section{Discussion}

A novel nucleoside antibiotic, A-94964 with a very unique structure containing a phosphoric acid diester, was isolated from the fermentation broth of the strain identified as Streptomyces sp. SANK 60404. A-94964 inhibited bacterial translocase I with $\mathrm{IC}_{50}$ value of $1.1 \mu \mathrm{g} / \mathrm{ml}$, and showed antimicrobial activities against Staphylococcus aureus and Enterococcus faecalis with MIC of 100 and $50 \mu \mathrm{g} / \mathrm{ml}$, respectively. The partial structures of A-94964 resembled those of tunicamycins, but the linkages of these structures are different from each other. So, we examined tunicamycins for their translocase I inhibitory activity. Tunicamycins showed $\mathrm{IC}_{50}$ values of $5.0 \mu \mathrm{g} / \mathrm{ml}$, indicating that A-94964 is five times more potent. In eukaryotes, it is known that tunicamycins inhibit UDP- $N$-acetylglucosamine: dolichol phosphate GlcNAc-1-P transferase (GPT) that catalyzes the first step in protein glycosylation [26] and show cytotoxicity for the mammalian cells. Then, we measured cytotoxic activities of A-94964 and tunicamycins against mammalian cell lines. While tunicamycins showed potent cytotoxicity $\left(\mathrm{IC}_{50}\right.$ values against $\mathrm{HeLa}$ and $\mathrm{A} 549$ were 0.075 and $0.072 \mu \mathrm{g} / \mathrm{ml}$, respectively), A-94964 showed no cytotoxicity up to $100 \mu \mathrm{g} / \mathrm{ml}$ against mammalian cell lines. So, it seems very likely that A-94964 do not show inhibitory activity for mammalian GPT, but a specific inhibitory activity for bacterial translocase I.

There are some compounds reported as translocase I inhibitors. Most of them are also natural products containing a nucleoside moiety and have unique spectra of antimicrobial activity. In recent reports, some synthesized analogues of pacidamycins [27], liposidomycins [28], capuramycin [29, 30] and caprazamycins [31, 32] showed broader spectrum and more potent antimicrobial activity.
Table 3 Antimicrobial activity of A-94964

\begin{tabular}{lc}
\hline \multicolumn{1}{c}{ Microorganism } & MIC $(\mu \mathrm{g} / \mathrm{ml})$ \\
\hline Staphylococcus aureus 123-1 & 100 \\
Streptococcus pyogenes 12255 & $>100$ \\
Streptococcus pneumoniae 2132 & $>100$ \\
Enterococcus faecalis 10785 & 50 \\
Enterococcus faecium 4288 & $>100$ \\
Moraxella catarrhalis 11045 & $>100$ \\
Escherichia coli NIHJ JC-2 & $>100$ \\
Klebsiella pneumoniae 806 & $>100$ \\
Enterobacter cloacae 963 & $>100$ \\
Serratia marcescens IAM 1184 & $>100$ \\
Haemophilus influenzae 11260 & $>100$ \\
Pseudomonas aeruginosa PAO1 & $>100$ \\
Mycobacterium smegmatis SANK 75075 & $>100$ \\
\hline
\end{tabular}

So, it seems likely that some chemical modification of A94964 may improve the inhibitory activity for translocase I and antimicrobial activity.

In the course of our screening for translocase I inhibitors, we identified various translocase I inhibitors containing some novel compounds from the culture broth of actinomycetes. The comparison of the taxonomic position based on 16S rDNA sequence of the strain SANK 60404 with that of other producing organisms of translocase I inhibitors indicated that strain SANK 60404 is distinct from other producing translocase I inhibitors including tunicamycin. Furthermore, it is notable that strains belonging to different species of Streptomycetes produce the same compounds. Because the partial structure of A-94964 resembles those of tunicamycins, it seems likely that strain SANK 60404 has similar biosynthetic genes with those of tunicamycins. Since biosynthetic pathway of the tunicamycins is not clear yet [33], strain SANK 60404 may contribute to study for biosynthesis of the tunicamycins and other nucleoside antibiotics.

\section{References}

1. Brandish PE, Kimura K, Inukai M, Southgate R, Lonsdale JT, Bugg TD. Modes of action of tunicamycin, liposidomycin $\mathrm{B}$ and mureidomycin A: Inhibition of phospho- $N$ acetylmuramyl-pentapeptide translocase from Escherichia coli. Antimicrob Agents Chemother 40: 1640-1644 (1996)

2. Inukai M, Isono F, Takahashi S, Enokita R, Sakaida Y, Haneishi T. Mureidomycin A D , novel peptidylnucleoside antibiotics with spheroplast forming activity. I. Taxonomy, fermentation, isolation and physico-chemical properties. J 
Antibiot 42: 662-666 (1989)

3. Karwowski JP, Jackson M, Theriault RJ, Chen RH, Barlow GJ, Maus ML. Pacidamycins, a novel series of antibiotics with anti-Pseudomonas aeruginosa activity. I. Taxonomy of the producing organism and fermentation. J Antibiot 42: 506-511 (1989)

4. Chatterjee S, Nadkarni SR, Vijayakumar EK, Patel MV, Ganguli BN, Fehlhaber HW, Vertesy L. Napsamycins, new Pseudomonas activity antibiotics of mureidomycin family from Streptomyces sp. HIL Y-82, 11372. J Antibiot 47: 595-598 (1994)

5. Ubukata M, Isono $\mathrm{K}$. The structure of liposidomycin B, an inhibitor of bacterial peptidoglycan synthesis. J Am Chem Soc 110: 4416-4417 (1988)

6. Takatsuki A, Arima K, Tamura G. Tunicamycin, a new antibiotic. I. Isolation and characterization of tunicamycin. J Antibiot 24: 215-223 (1971)

7. Yamaguchi $\mathrm{H}$, Sato $\mathrm{S}$, Yoshida $\mathrm{S}$, Takada $\mathrm{K}$, Itou $\mathrm{M}$, Seto $\mathrm{H}$, Otake N. Capuramycin, a new nucleoside antibiotic. Taxonomy, fermentation, isolation and characterization. J Antibiot 39: 1047-1053 (1986)

8. Seto H, Otake N. The structure of a new nucleoside antibiotic, capuramycin. Tetrahedron Lett 29: 2343-2346 (1988)

9. Muramatsu Y, Muramatsu A, Ohnuki T, Ishi MM, Kizuka M, Enokita R, Tsutsumi S, Arai M, Ogawa Y, Suzuki T, Takatsu T, Inukai M. Studies on novel bacterial translocase I inhibitors. I. Taxonomy, fermentation, isolation, physicochemical properties and structure elucidation of A-500359A, C, D and G. J Antibiot 57: 243-252 (2003)

10. Muramatsu Y, Ishii MM, Inukai M. Studies on novel bacterial translocase I inhibitors, A-500359s. II. Biological activities of A-500359 A, C, D and G. J Antibiot 56: 253 258 (2003)

11. Muramatsu Y, Miyakoshi S, Ogawa Y, Ohnuki T, Ishii MM, Arai M, Inukai M. Studies on novel bacterial translocase I inhibitors, A-500359s. III. Deaminocaprolactam derivaties of capuramycin: A-500359 E, F, H, M-1 and M-2. J Antibiot 56: 259-267 (2003)

12. Ohnuki T, Muramatsu Y, Miyakoshi S, Takatsu T, Inukai M. Studies on novel bacterial translocase I inhibitors, A500359s. IV. Biosynthesis of A-500359s. J Antibiot 56: 268-279 (2003)

13. Muramatsu Y, Arai M, Sakaida Y, Takamatsu Y, Miyakoshi $\mathrm{S}$, Inukai M. Studies on novel bacterial translocase I inhibitors, A-500359s. V. Enhanced production of capuramycin and A-500359A in Streptomyces griseus SANK 60196. J Antibiot 59: 601-606 (2006)

14. McDonald LA, Barbieri LR, Carter GT, Lenoy E, Lotvin J, Petersen PJ, Singh G, Williamson RT. Structures of the muraymycins, novel peptidoglycan biosynthesis inhibitors. J Am Chem Soc 124: 10260-10261 (2002)

15. Igarashi M, Nakagawa N, Doi N, Hattori S, Naganawa H, Hamada M. Caprazamycin B, a novel anti-tuberculosis antibiotic, from Streptomyces sp. J Antibiot 56: 580-583 (2003)
16. Igarashi M, Takahashi Y, Shibata T, Nakamura H, Naganawa H, Miyake T, Akamatsu Y. Caprazamycins, novel liponucleoside antibiotics, from Streptomyces sp. II. Structure elucidation of caprazamycins. J Antibiot 58: 327-337 (2005)

17. Fernandes PB, Swanson RN, Hardy DJ, Hanson CW, Coen L, Rasmussen RR, Chen RH. Pacidamycins, a novel series of antibiotics with anti-Pseudomonas aeruginosa activity. III. Microbiologic profile. J Antibiot 42: 521-526 (1989)

18. Isono F, Kodama K, Inukai M. Susceptibility of Pseudomonas species to the novel antibiotics mureidomycins. Antimicrob Agents Chemother 36: 1024-1027 (1992)

19. Shirling EB, Gottlieb D. Methods for characterization of Streptomyces species. Int J Syst Bacteriol 16: 313-340 (1966)

20. Waksman SA. Classification, identification and description of genera and species. The Actinomycetes. Vol. II, pp. 328-334, Williams \& Wilkins (1961)

21. Hasegawa T, Takizawa M, Tanida S. A rapid analysis for chemical grouping of aerobic actinomycetes. J Gen Appl Microbiol 29: 319-322 (1983)

22. Nakagawa Y, Kawasaki H. Identification Manual of Actinomycetes. (edited by The Society for Actinomycetes Japan, Business Center for Academic Societies Japan, Tokyo, Japan), pp. 83-117 (2001) (Japanese)

23. Saitou N, Nei M. The neighbor-joining method: a new method of constructing phylogenetic tree. Mol Biol Evol 6: 514-525 (1987)

24. Tamura K, Dudley J, Nei M, Kumar S. MEGA4: Molecular Evolutionaly Genetics Analysis (MEGA) Software Version 4.0. Mol Biol Evol 24: 1596-1599 (2007)

25. Mosmann T. Rapid colorimetric assay for cellular growth and survival: application to proliferation and cytotoxic assays. J Immunol Methods 65: 55-63 (1983)

26. Heifetz A, Keenan RW, Elbein, AD. Mechanism of action of tunicamycin on the UDP-GlcNAc: dolichyl phosphate GlcNAc-1-phosphate transferase. Biochemistry 18: 21862192 (1979)

27. Constantine GB, Remy CL, Johanne B, Nicole GV, Karin AS, Angela M, Suzanne C, Scott JH, Ving JL. Synthetic dihydropacidamycin antibiotics: A modified spectrum of activity for the pacidamycin class. Bioorg Med Chem Lett 13: 3305-3309 (2003)

28. Dini C, Didier-Laurent S, Drochon N, Feteanu S, Guillot JC, Monti F, Uridat E, Zhang J, Aszodi J. Synthesis of submicromolar inhibitors of MraY by exploring the region originally occupied by the diazepanone ring in the liposidomycin structure. Bioorg Med Chem Lett 12: 12091213 (2002)

29. Hotoda H, Furukawa M, Daigo M, Murayama K, Kaneko M, Muramatsu Y, Ishi MM, Miyakoshi S, Takatsu T, Inukai M, Kakuta M, Abe T, Harasaki T, Fukuoka T, Utsui Y, Ohya S. Synthesis and antimycobacterial activity of capuramycin analogues. Part 1: Substitution of the azepan-2-one moiety of capuramycin. Bioorg Med Chem Lett 13: 2829-2832 (2003) 
30. Hotoda H, Daigo M, Furukawa M, Murayama K, Hasegawa AC, Kaneko M, Muramatsu Y, Ishi MM, Miyakoshi S, Takatsu T, Inukai M, Kakuta M, Abe T, Fukuoka T, Utsui Y, Ohya S. Synthesis and antimycobacterial activity of capuramycin analogues. Part 2: Acylated derivatives of capuramycin-related compounds. Bioorg Med Chem Lett 13: 2833-2836 (2003)

31. Miyake T, Takahashi Y, Igarashi M, Doi N, Shitara T, Sohtome H, Iijima K, Masuda T, Hattori S, Nakagawa N, Akamatsu Y. Novel semisynthetic antibiotics from caprazamycins (Part 1): Caprazene derivatives and their antiMycobacterium tuberculosis activity. 43rd Interscience
Conference on Antimicrobial Agents and Chemotherapy (ICAAC), Abstracts F-2140 (2003)

32. Miyake T, Shitara T, Igarashi M, Doi N, Takahashi Y, Sohtome H, Iijima K, Masuda T, Hattori S, Nakagawa N, Akamatsu Y. Novel semisynthetic antibiotics from caprazamycins (Part 2): Caprazol derivatives and their antiMycobacterium tuberculosis activity. 43rd Interscience Conference on Antimicrobial Agents and Chemotherapy (ICAAC), Abstracts F-2141 (2003)

33. Price NPJ, Tsvetanova B. Biosynthesis of the Tunicamycins: A Review. J Antibiot 60: 485-491 (2007) 